\title{
Multimodality as an Interactional Resource for Classroom Interactional Competence (CIC)
}

\author{
Jaeuk Park a * (D) \\ a Newcastle University, Newcastle Upon Tyne, UK
}

Received 17 July 2017 | Received in revised form 5 September 2017 | Accepted 5 September 2017

\begin{abstract}
This paper of action research discusses the emergent progress of multimodality in the classroom interaction. Despite the pivotal role of multimodality in interaction in the foreign language classroom, little attention has been paid to how embodied behaviours are used as a resource by students in relation to Classroom Interactional Competence (CIC). The study, therefore, aims to assess how multimodality influences learning from learner's perspectives. The data for this study is based on the video-recording of an English grammar lesson for adult learners. Drawing on a Conversation Analysis (CA) approach to look into the interactional unfolding of multimodal behaviours, this study uncovered the potential impact of multimodality on interaction in a foreign language classroom. The findings have significant implications for research on CIC and language teacher education.
\end{abstract}

(C) 2017 EJAL \& the Authors. Published by Eurasian Journal of Applied Linguistics (EJAL). This is an open-access article distributed under the terms and conditions of the Creative Commons Attribution license (CC BY-NC-ND) (http://creativecommons.org/licenses/by-nc-nd/4.0/).

Keywords: Classroom Interactional Competence (CIC), learning, multimodality, CA, teacher education

\section{Introduction}

Recent decades have seen a rising interest in the role and function of multimodality in interaction in the field of SLA. Multimodal social behaviours engaged in by an adult and a child help interact with each other as if adult teacher helps young students through dialogue and scaffolding, according to Liszkowski (2010). This is perhaps an example of adults scaffolding infants in a multimodal way and interaction on the interpsychological plane, which the children will later internalise on the intrapsychological plane (Vygotsky \& Cole, 1978). Learning, from this perspective, involves dialogue, discussion, and debate as learners collectively construct their own understanding through interactions with others who are in a position to help and support the actions. Based on the support channel and interactional space that learners are given by the tutor, opportunities for learning are maximised. The learning space is created and maximised generally by multi modes of both verbal and non-verbal communication, which enable teachers and learners to see the co-

\footnotetext{
* Jaeuk Park.

E-mail address: j.u.park@ncl.ac.uk

http://dx.doi.org/...
} 
construction of meaningful classroom discourse (Walsh, 2006). In this regard, it is important to examine multimodality as a resource for interactional competence concerned with what occurs between interactants and how that communication is managed by analysing classroom discourse under explanation. However, much less empirical work that explores how multimodality influences classroom interaction from learners' point of view has been done.

By understanding learners' embodied behaviours, this action research, therefore, aims to examine how the use of the multimodal resources in the foreign language classroom can construct or obstruct learning-in-interaction and, based on the findings, how teachers' pedagogical practices can be improved. Building on findings put forth by Sert (2015) that multimodal behaviours presented by teachers in L2 classroom 'sine qua non play a key role in meaning-making processes that may be conducive to the successful management of pedagogical activities as well as to creating learning opportunities' (p. 87), this paper contributes to previous literature by taking students' perspectives in Classroom Interactional Competence (CIC). The following research questions guided the study: (a) what multimodal resources do students use to carry out interactional activity in response to a teacher's grammar explanation? and (b) how does their use of multimodality influence learning when interacting with peers and their teacher?

In what follows, I will first review the literature in relation to multimodality and (classroom) interactional competence along with the relevant methodology. Then, I will analyse examples demonstrating cases of multimodal resources being used and their influences on the social action of understanding in the classroom context, and summarise the findings with respect to teacher education.

\section{Literature Review}

\subsection{Multimodality}

Stivers and Sidnell (2005) propose that 'different modalities work together not only to elaborate the semantic content of talk but also to constitute coherent courses of action' (p. 1). In this sense, the notion of multimodality needs to be addressed. The notion can be defined as the coordinated deployment of nonverbal resources such as gesture and body display, as well as verbal and para-verbal channels such as syntax and prosody (ibid). The multimodality helps to 'reinstate partial elements of the reality of discourse, giving each speaker and each conversational episode a specific distinguishable identity, allowing users to explore contextual and co-textual elements of discourse in more depth', according to Knight (2011, p. 205). Her argument shows that both resources are interrelated and have an impact on a speaker's behaviour in relation to the particular linguistic and social context.

As well as in social context, multimodality has been known to play important roles in educational contexts, in particular, in interactions between students and teachers in several ways. To begin with, resources such as gestures, gaze and silence make a 
big difference in spoken ability and communication. Houser and Frymier (2009) noted the role of those resources in the development of student empowerment and achievement, demonstrating the importance of multimodal channels in student oral development. Gullberg (1998) examined the use of gestures as communication strategies, as opposed to oral communication strategies, showing individual differences in the amount and types of gestures used. This multimodal behaviour is further studied in a different context by Sime (2006), who found that gestures and other nonverbal behaviours play a key role in the language learning process, identifying three types of functions in EFL classroom interaction: cognitive, emotional and organisational. Sert (2011) revealed that gaze and silence serve as a means by which teachers can interpret students' lack of knowledge, offering in-depth analysis on students' epistemic status. Thus, considering the potential impact that nonverbal channels have, it is critical that all instructors should be aware of students' personal outward nonverbal projection, as well as observation of students' nonverbal cues.

Interestingly, multimodality has been paid little attention in relation to CA as the main focus and interest in CA research have been on vocal conduct in interaction. That is how participants carry out and organize their social actions through talk-ininteraction. However, early researchers cover not only talk but also gaze (Goodwin, 1979, 1981), gestures (Shegloff, 1984) and bodily movements (Heath, 1986) as part of the components of social interaction. These studies have set the stage for a significant vein of research into embodied interaction, multimodal interaction or multimodality. Mondada $(2006,2007)$ has recently provided extensive analyses of how multimodal resource can be mobilised by participants to organise their social actions from CA perspective.

A number of studies have taken a conversational analytic investigation into multimodality in the context of second language acquisition. Mortensen (2008, 2009) showed that semiotic aspects through body orientations, pointing and nods play a role in turn-allocation in a foreign language classroom. Eskildsen and Wagner (2013) proposed that 'vocabulary is learned and taught and accompanied by recurring gestures that have emerged from shared interactional spaces' (p. 158). Embodied behaviours function as crucial interactional resources, by which teachers instruct as well as assess students' performance and learners use the embodied resources to display their understanding of the pedagogical activity in the ESL grammar context (Matsumoto \& Dobs, 2017). These studies indicate that meaning and functions suggested by participants in a particular context depend as much on nonverbal cues as on verbal ones. These findings situate multimodality as an interactional strategy at the crossroads of interactive concerns in the classroom interactional competence study.

\subsection{Classroom Interactional Competence}

Applying the notion of Interactional Competence (IC) to the classroom discourse, Walsh (2011) coined Classroom Interaction Competence (CIC), which is defined as 
'teachers' and learners' ability to use interaction as a tool for mediating and assisting learning' (p. 132). He demonstrated three key features of CIC; (a) the use of pedagogically convergent language, which is appropriate to learners; (b) creating interactional space (i.e. extensive use of pause, a lack of repair, signposting in instructions, extended learner turns and echo); (c) shaping learner contribution (i.e. seeking clarification, scaffolding, modelling or repairing learner input. One of the distinct important interactional resources available is multimodality. Indeed, learners' multimodal cues in response to teachers' explanation are important realtime feedback that influence teachers' subsequent interaction (Suinn, 2006), and allow teachers to alter their course of action if necessary (Davis, 2009). Webb et al. (1997) states that observing student's multimodality enables the insightful teacher to decide whether it is necessary to 'check for students' comprehension, provide more or a different kind of instruction, or assign more practice' (p. 89). Thus, multimodality can be used to see how learners show their understanding and how they shape their contribution to the classroom interaction. The way it is used in the classroom among peers, and between a teacher and a learner encourages us to reflect on the meaning of learning.

Following Walsh's development, CIC have been studied widely from different perspectives in different settings (Can Daşkın, 2015; Escobar Urmeneta, 2013; Escobar Urmeneta \& Evnitskaya, 2014; Sert, 2011; Sert, 2015). Escobar Urmeneta (2013) aimed to improve teachers' professional development in a Spanish context, using multimodal CA and content analysis. She showed how a novice teacher make progress in CIC when dealing with challenges in a content and language integrated learning (CLIL) education programme through useful tools of collaborative teaching and shared reflection. Spurred on by this research, Escobar Urmeneta and Evnitskaya (2014) conducted a study in the same context, demonstrating that multimodal resources can be employed to develop teachers' CIC. Their findings showed that teachers' efficient deployment of multimodal resources constructs learner-initiated turns, thereby helping students to shape the contribution. This study contributed to the characterisation of CIC components. Elaborating on the feature of CIC, Can Daşkın (2015) examined the interactional pattern for shaping learner contributions in an EFL context. The author showed various interactional patterns in sequential organisation in classroom contexts, contributing to building up two more features of CIC: translation to L1/L2 and the use of board. Very recently, drawing on a construct of CIC, Matsumoto and Dobs (2017) have given strong support to the dialogic and pedagogical role of multimodality as a resource for establishing intersubjectivity between teachers and students in ELF contexts.

Yet, very often, the main focus has been from teachers' perspectives, and researchers have paid insufficient attention to non-verbal phenomena in a foreign language learning classroom. Sert $(2011,2015)$, in particular, revealed that multimodal resources of interaction play a prominent role in understanding pedagogical practices and that multimodality are employed for teachers and learners to display CIC. Nevertheless, little research has delved in any depth in to how 
multimodality is employed as a resource by learners that contributes to CIC in the classroom interaction. The current study, therefore, seeks to contribute to such work done on multimodality and learning opportunities by evaluating and assessing the impact of multimodality as interactional resources on learning and suggesting how we, as instructors, make changes to our teaching practices in the classroom.

\section{Method}

The data for this study is based on one of the International House Teacher Training DVDs, the video-recording of lessons taught in English by International House London teachers for adult learners in a pre-intermediate multilingual class. A grammar lesson was chosen, in which an instructor and six students were recorded. Transcriptions were ready made available at Newcastle University, but the researcher had to observe the episodes in points for precise transcription.

What was chosen for investigation in this grammar lesson was question-answer activity between a teacher and students or peers themselves. To be specific, it was the lesson that helped students revise various prepositions of place which had already been exposed to them earlier in the course. To minimise methodological flaws and maximise the chance of examining specific aspects of multimodal behaviours in classroom interaction, the data was taken from two cameras, in two different corners of the classroom which recorded the teacher-students and student-student interactions. Each section, in which the learner's use of multimodality was especially evident, was marked and transcribed by the researcher using the Jeffersonian transcription convention developed for researchers in conversation analysis. The transcription conventions allow for a precise notation of prosodic features and voice quality. In the extracts shown below, nonverbal cues and their alignment with verbal resources are transcribed in separate lines and by using a different font to show the evidence in the data. The transcription conventions for the analysis are listed in the appendix.

The present study draws upon a CA approach to look into the mechanism of connected discourse. It is an analytical method that offers insight into how people organise their conduct to achieve their daily affairs that occur naturally during talkin-interaction. Ten Have (2007) insists that CA allows researchers to investigate the data with special attention given to the details of interaction represented by a detailed transcript. Furthermore, CA offers valuable understanding on the fine details of learner interaction and on how they use their language resources to socialise within the small group discussions to show 'understanding and knowing' (Koole \& Elbers, 2014). The work will benefit from the CA's emic perspective, a feature that Markee and Kasper (2004) define as an empirically observed conversational conduct rather than a state of mind obtained by an interview. However, the overall aim of this study is to reveal nonverbal multimodal cues that learners use as an interactional resource to perform the specific interactive activity. Both verbal and non-verbal communication channels can 'work together not only to elaborate the semantic content of talk but also to constitute coherent courses of action' (Stivers \& Sidnell, 2005, p. 1). The CA concept 
needs to be broadened to cover verbal resources as well as participants' visual displays to analyse multimodal interaction (Stukenbrock, 2009a, cited by Kupetz, 2011). CA is also 'well equipped to study' multimodal language learning behaviours (Sert, 2015, p. 106). Likewise, linguistic resources as well as nonverbal channels were analysed in order to account for the full cluster of resources that can be involved in social activities in the classroom.

\section{Results}

\subsection{Spatial configuration for meaning making}

Extract 1 given below is a typical example of the interactional resource learners use in a question-answer activity of learning in the classroom: the teacher encourages a student to come up to the front to match a word and a photo. It is obvious that a learner integrates verbal and nonverbal channels of gestures and space for meaning making, which in turn results in a teacher's evaluation, impacting the flow and coherence of the discussion between L1 and a teacher.

\section{Extract 1}

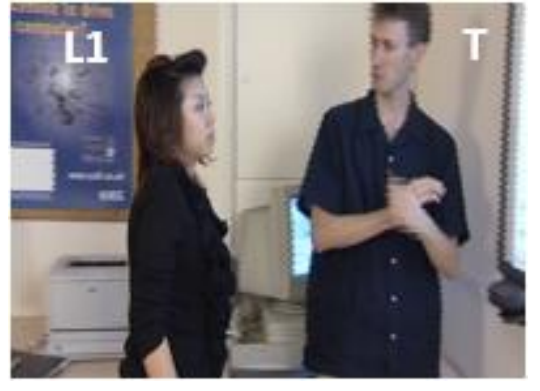

Figure 1

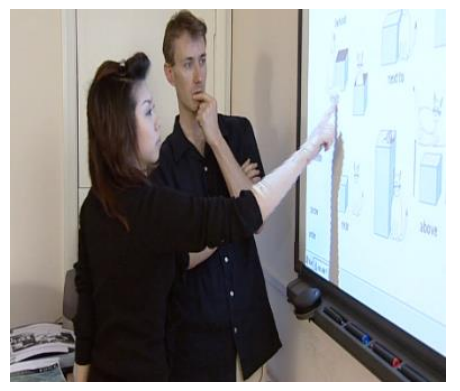

Figure 2

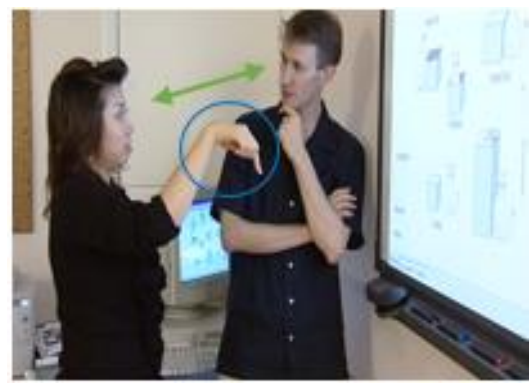

Figure 3

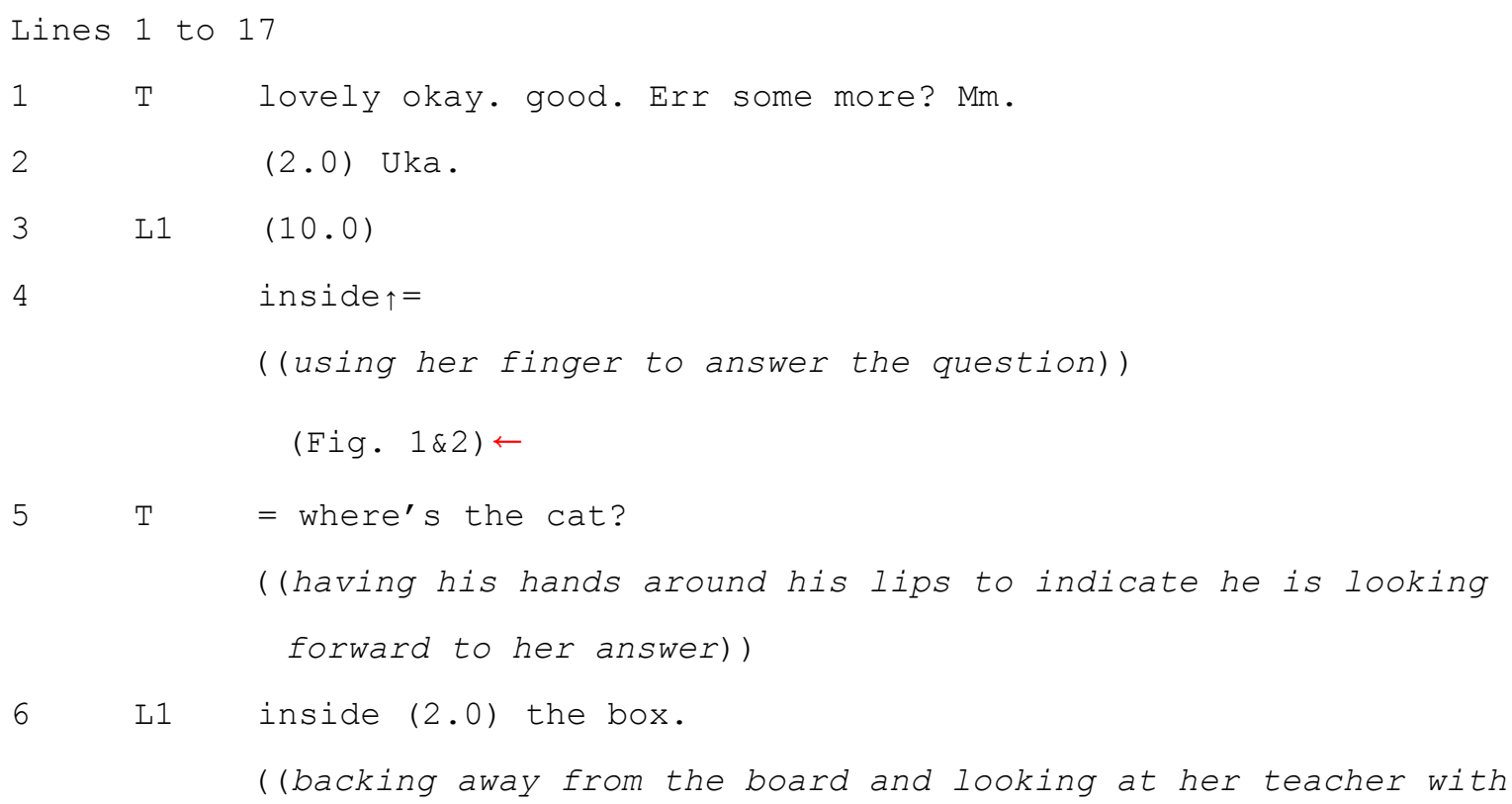




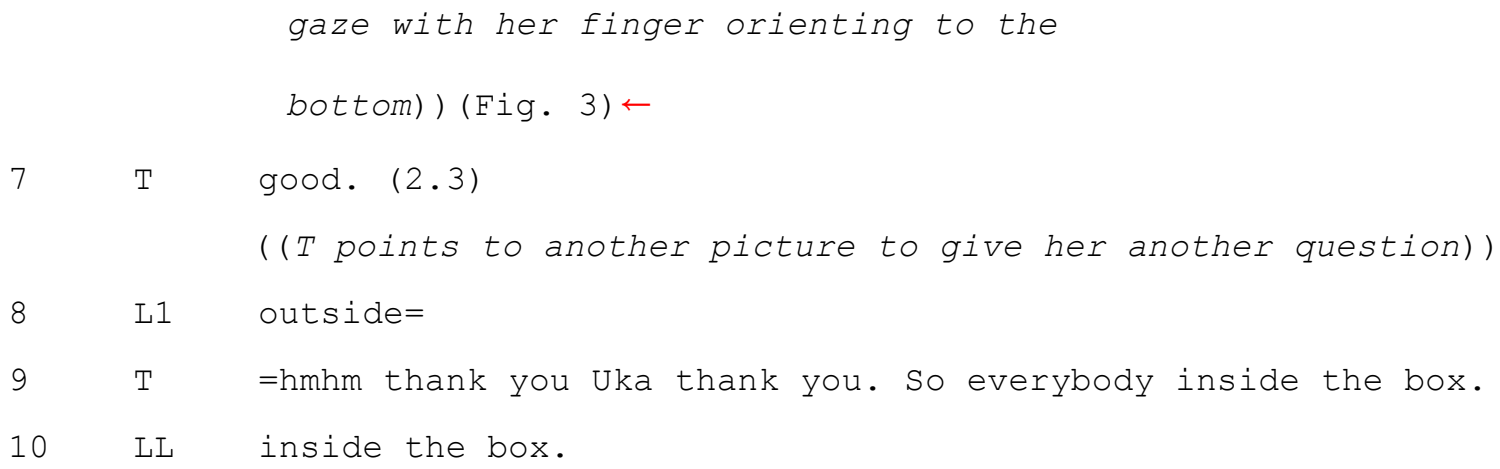

On the teacher's question, L1 uses the word 'inside' (line 4) with rising tone at the end, sounding like she is seeking confirmation from the teacher. However, the teacher asks her to be more precise by asking a specific question and by placing his hand around his lips suggesting he wants a clearer answer (line 5). Being aware of the need to elaborate on her answer to complete her task, she adds more syntactic words to specify her explanation in line 6. Interestingly, she relies not just on words but also on her body. She is reconfiguring the spatial arrangement (Figure 3) (Mondada, 2009, 2011) by backing away from the board and by making large arm movements to give him a more elaborated answer. This way, she creates a new, larger interactional space' (Walsh, 2011) which enables her to 'perform' her learning activity. Within this new interaction space, she signals her meaning by her nonverbally voluminous hand gesture and verbal description. Her confirmation checking is immediately followed by the teacher's content feedback and another question, in line 7, to double check whether or not the student got the meaning right. On her correct answer, a teacher assesses her performance by thanking and calling L1 in line 9. Her well-performed activity allows a teacher to contribute to other students' confirmation checking of the grammar by invoking a public repetition in lines 9-10.

Extract 1 shows what and how the learner depends on to reformulate her learning activity. In recognition of ambiguity, she displayed multimodal behaviours to convey the meaning by counting not only on semantic and syntactic, but on spatial resources, by which she clarifies the social activity of learning, thereby constructing a teacher' comprehension. The combination of verbal and spatial resources by a learner plays a significant role in reaching intersubjectivity (i.e. shared understanding) and alignment between participants, as well as other students. Furthermore, her use of classroom artefact of the whiteboard as a multimodal resource (Hennessy, 2011) was meaningful as it helped clarify the contribution and make public her pedagogical performance to colleagues, showing her interactional competence in the classroom. Thus, it can be claimed that it is the deployment of multimodality which enabled her to hold the floor and elucidate the meaning at a particular point in the interaction of the activity, displaying her CIC.

\subsection{Deictic gestures for turn-taking}

Other nonverbal signals that students may use to embody their interactional resource are gaze and head movement. Extract 2, given below, is where the teacher 
encourages students to do pair work. In particular, following the teacher's explanation, they are asked to give each other questions where they should practice prepositions. It is clear that a learner draws on diverse body movements for turn management, which influences the flow of the interaction between learners.

\section{Extract 2}

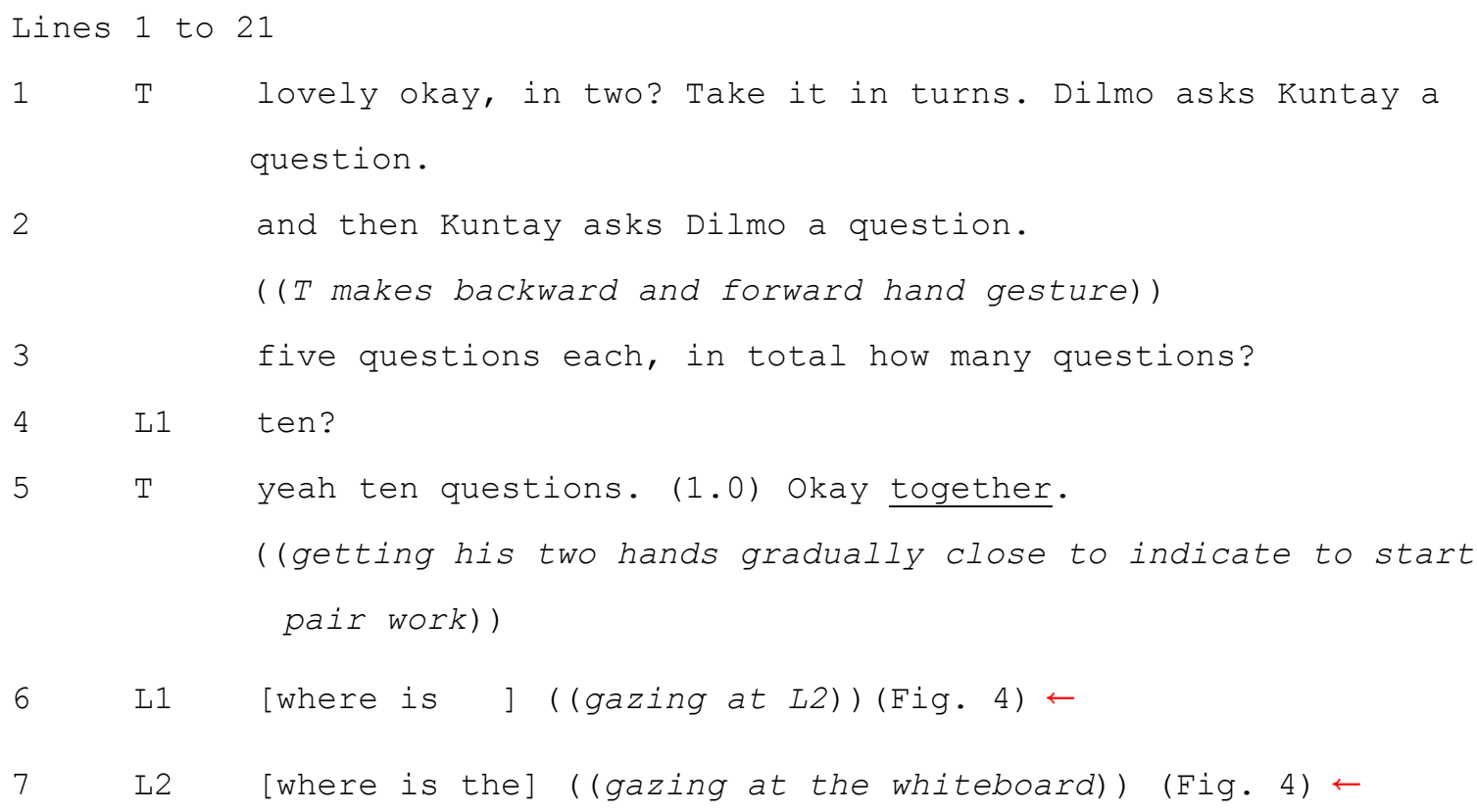

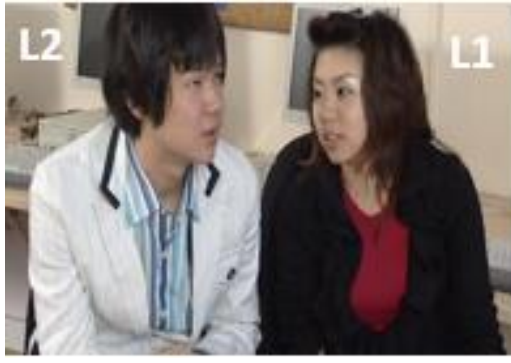

Figure 4

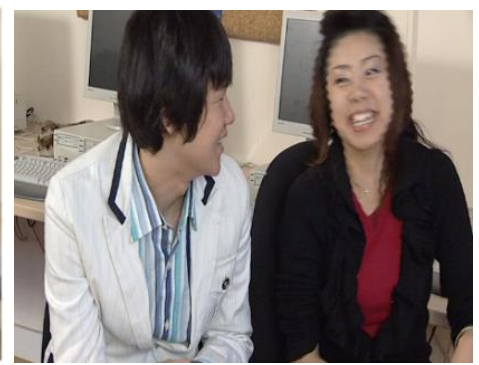

Figure 5

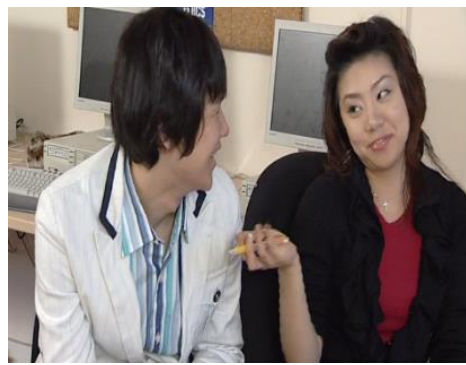

Figure 6

8 L1 [hahaha]

((looking at L2 with tilted head and smile)) (Fig. 5) $\leftarrow$

$9 \quad$ L2 [hahaha]

((gazing at L2 to choose the next speaker)) (Fig. 5) $\leftarrow$ $(2.0)$

10 L1 (smiling widely to avoid the atmosphere, and giving L2 hand gesture to indicate L1 wants L2 to start)) (Fig. 6) $\leftarrow$

11 L2 where is the cat number five in the picture picture? 


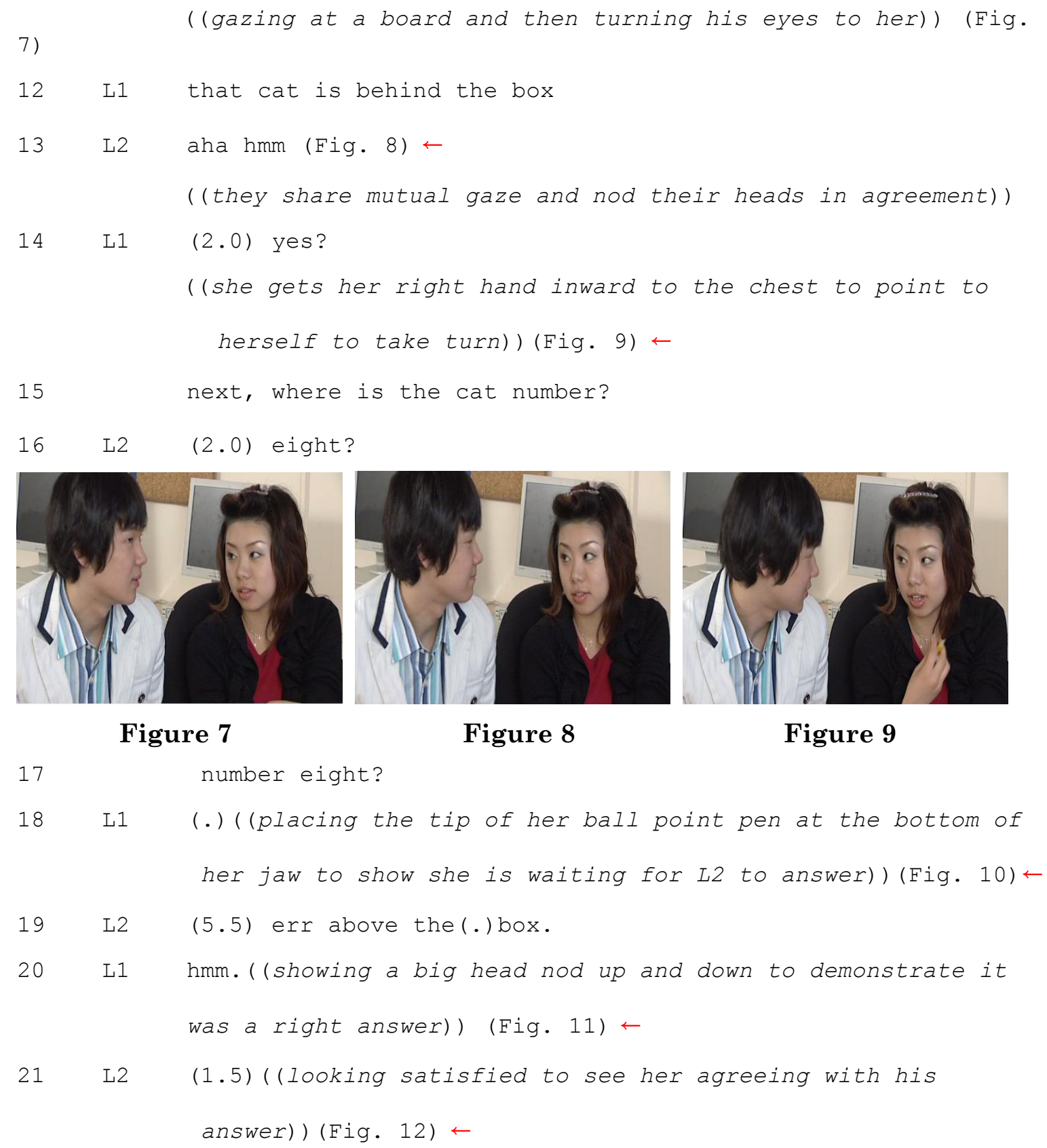

Figure 7

Figure 8

Figure 9

17 number eight?

18 L1 (.)( (placing the tip of her ball point pen at the bottom of

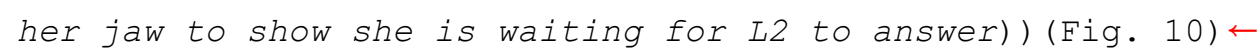
19 L2 (5.5) err above the (.) box.

20 L1 hmm. ( showing a big head nod up and down to demonstrate it was a right answer)) (Fig. 11) $\leftarrow$

21 L2 (1.5)(llooking satisfied to see her agreeing with his answer) ) (Fig. 12) $\leftarrow$

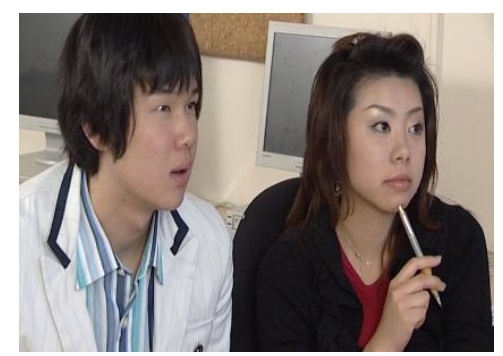

Figure 10

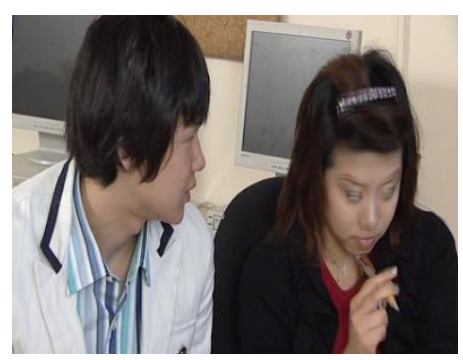

Figure 11

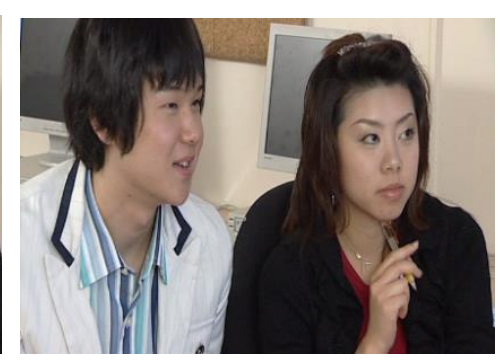

Figure 12

Following the teacher's instruction for the task (lines 1 to 5), two learners attempt to allocate turns to each other. Since there is no explicit turn allocation, they try to yield a turn by asking a question at the same time (lines 6 to 7). Recognizing overlap, 
L1 seems to lead the moment as she smiles and laughs in lines 8 to 9 (Fig. 5) to avoid the awkward atmosphere and then finally gives her way to L2 (him) by showing hand gesture in line 10 (Fig. 6) to indicate that she wants him to begin to take turn. Realising the turn offered by her, he carries out the pedagogical activity both by asking her a question and by drawing on embodied behaviours in line 11 (Fig. 7). He looks at the whiteboard and then turns his eyes to her to indicate he is waiting for her answer, during which she is aware of her turn and answers the question (line 12). L2 gives her acknowledgement tokens 'aha hmm', while the duo share mutual gaze and nod their heads in agreement with the answer in line 13 (Keevallik, 2014). This is the moment where turn transition occurs and the next speaker should be selected. The next pause of 2.0 seconds shows that there is no obvious signal for the next turn following her answer, which allowed none of them to establish who should take the next one (Fig. 8). It is then that she mobilises not only linguistics resources of 'yes' but also deictic gestures of getting her right hand inward (Fig. 9) to the chest to point to herself in line 14 to ask if it is ok for her to take turn (Mondada, 2007). That is, she finds herself in the same situation as in line 10, and takes action to solicit her turn (Iwasaki, 2015) by way of multimodality. Furthermore, overlaps in lines 6 to 9 demonstrate the interaction carries on smoothly. According to McCarthy (2003), the overlap is indicative of good 'listenership', showing that the channels are open and that the communication is working well. Overlaps give two learners important clues that speakers are being understood (Walsh, 2011).

Up until the turn is completed (lines 15 to 20), she keeps mobilising every necessary means such as head, facial looks, hand and a classroom artefact to show her meaning. To L1's confirmation check, she gets the tip of her ball point pen at the bottom of her jaw attached (Fig. 10) to show she is still waiting for him to answer the question. It leads him to a long pause (5.5 secs.) where he tries to come up with the answer in line 18. To his answer in line 20, while producing agreement marker of ' $\mathrm{hmm}$ ', she simultaneously moves her head dynamically up and down (Fig. 11) to admit it sounds right, during which he looks satisfied to know it was a right answer to the question (Fig. 12) in line 21. Thus, learners were seen to draw on two modes of linguistic and non-linguistic channels to show what both parties mean and to signal understanding, thereby co-constructing meanings in the interaction at the given time. Therefore, multimodal channels can be said to play a crucial role as an interactional resource in the classroom interaction. Drawing on Extract 2, some initial observations can be made with regards to interactional resource and classroom interactional competence.

Extract 2 demonstrates that when learners are required to do activity in pairs following the teachers' grammar explanation, they tend to use both verbal and nonverbal channels to interact with each other. She explicitly uses her hand gestures, interpersonal gaze, nods and an artefact, all of which were followed by his question for her and his answer to her question along with yet another nonverbal channels. Drawing on these strategies, she knows how to manage her own turn-taking. Nonverbal channels synchronized with speech were also found to become a useful interactional resource for learners to not only demonstrate current understanding but 
keep the classroom discourse. Thus, the coordination of multimodality makes their turns coherent and meaningful, displaying learners' CIC.

\subsection{Resource to facilitate or block Interactional Space}

The next extract clearly shows that a learner uses multimodality as a turnrequesting device, and also indicates how multimodality influences learning by identifying two episodes, one where learner's multimodal behaviour create learning opportunities, and the other where the mistake of teacher's inaction for learner's appeal to shape the contribution hinders learning. The teacher nominates a student to guess on what is shown on the board.

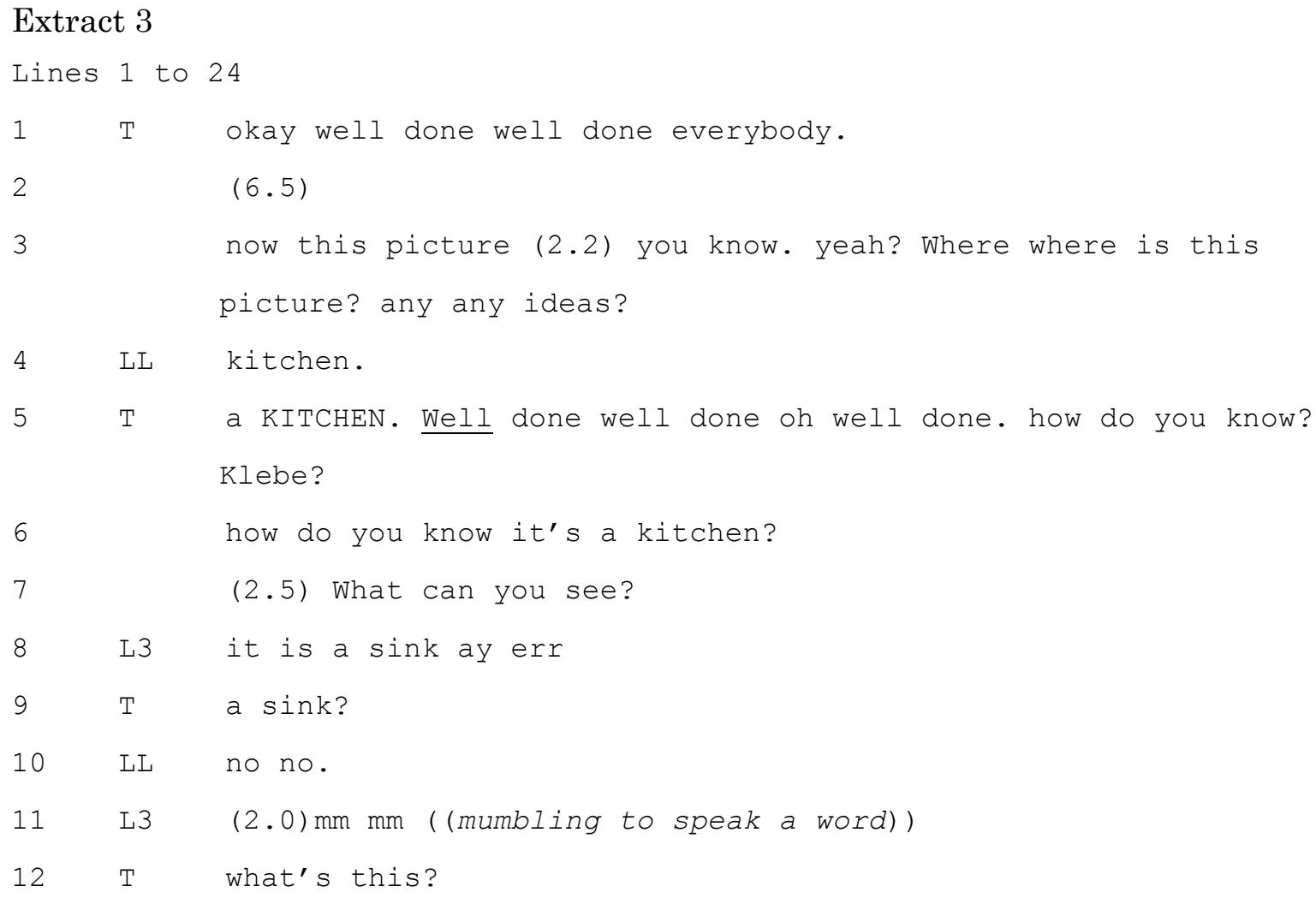

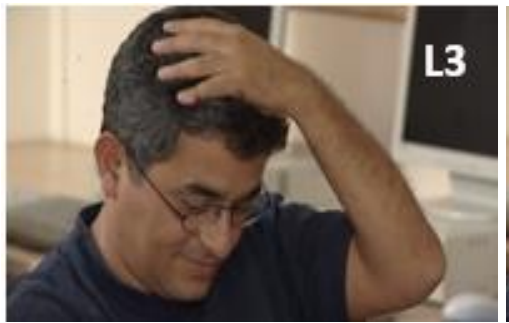

Figure 13

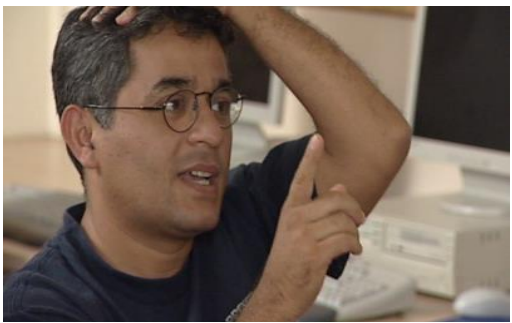

Figure 14

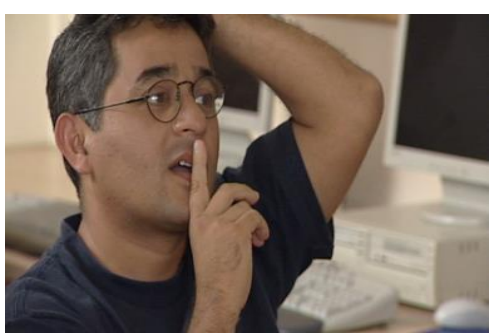

Figure 15
13 L3
$(2.5)$
( (banging head with his left hand))
(Fig. 13)
$14 \mathrm{~T}$
$(3.0)$ 


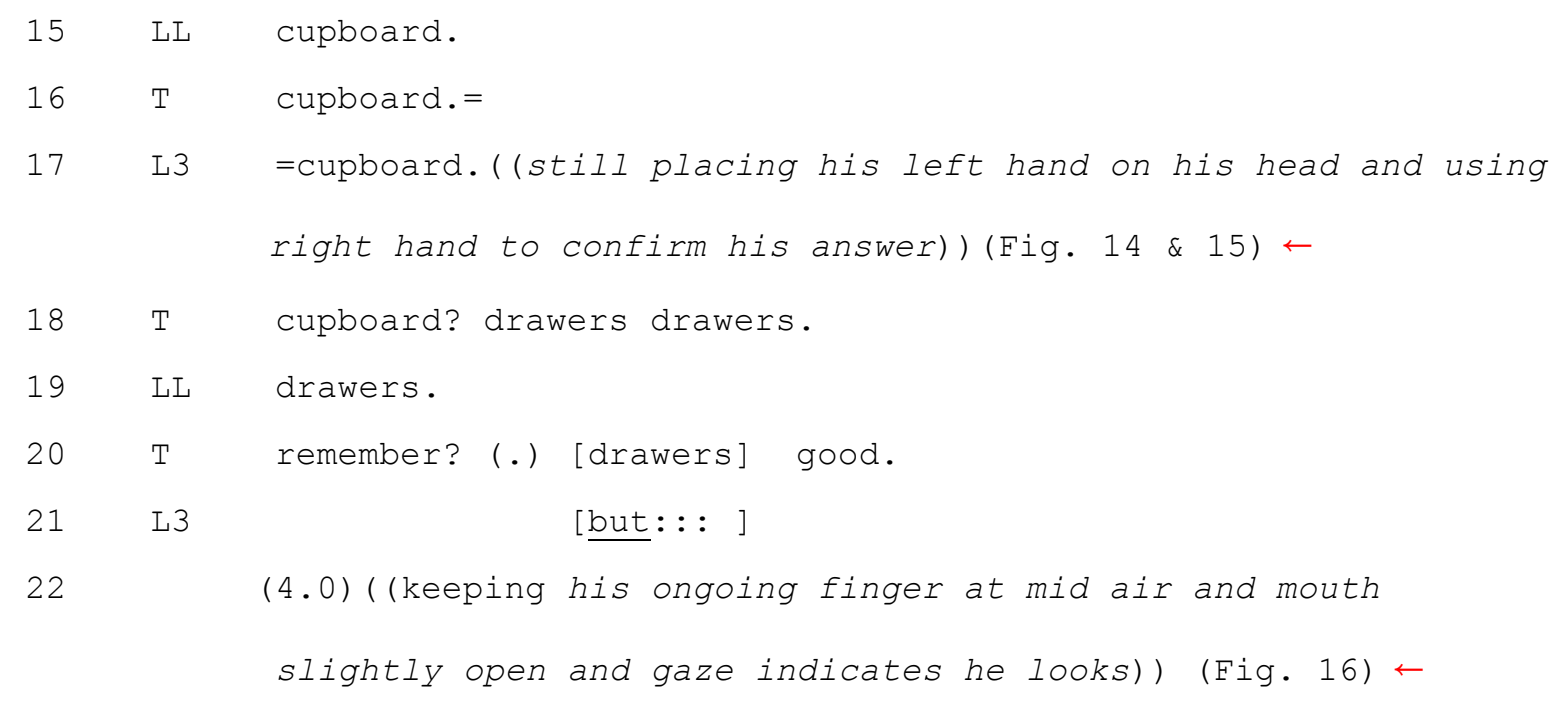

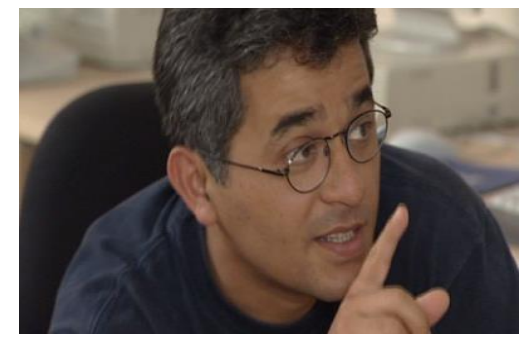

Figure 16

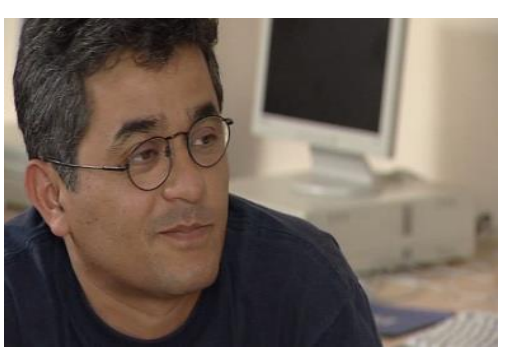

Figure 17

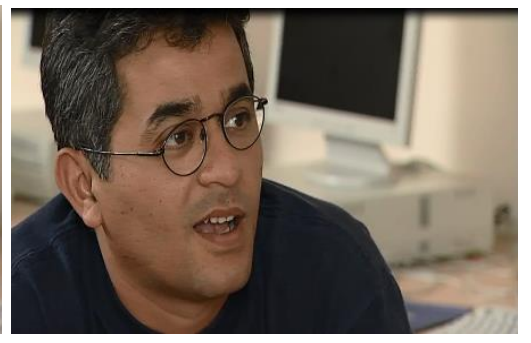

Figure 18

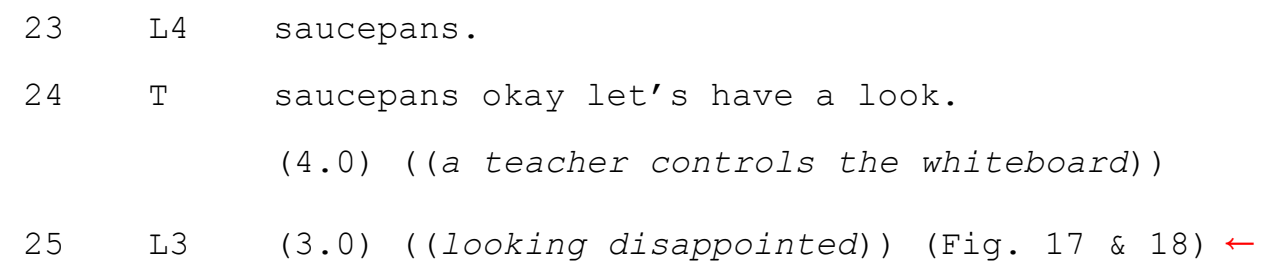

When publicly nominated to answer the question (lines 1 to 12), L3 mumbles (line 11) to come up with a word banging his head with left hand (Figure 13). This suggests that he is trying to think of the right answer (line 13) while keeping his left hand on his head to think of the correct answer. Keeping his left hand on his head indicates that he is requesting his continuous turn. This subsequently prevents the teacher interrupting L3, allowing him to extend his turn for 3 more seconds (line 14). This provides L3 with an opportunity to contribute to the interaction, during which interestingly, other students help L3's reply to a teacher's question in line 15 by collectively suggesting a possible answer. It demonstrates that other learners take his bodily movements as a public sign for help. Then, L3 repeats after their answer in line 17 (Figure 14). In other words, embodied cues serve as a mediator to cause other students to collaboratively interact, which in turn, results in another space where a teacher can correct their answer in lines 18 to 20 . In the process of this pedagogic activity, multimodality is shown to facilitate an interactional space where perceived teacher offers student-in-interaction opportunities to contribute, and other students 
can be involved. The interplay of speech and body is found to play a crucial role in the interaction, enhancing mutual understanding. The embodied 'catchment' by all participants are evidences of interactional alignments (Matsumoto and Dobs, 2017, p. 29) .

However, there is a need to note that in lines 21 to 25 , a teacher blocks a space for learning. L3 conveys explicit meaning that he wants to take his turn to give it his own idea by verbally saying but in line 21 . He even attempts to speak by using his direct gaze and pointing gesture as in Figure 16 in line 22. Considering his ongoing fingerpointing and gaze, he looks like he noticeably wants a teacher to yield him another chance to speak, and he even half stands up and sits down on a chair to grab the teacher's attention but the teacher does not perceive in a video-clip. Eventually, L3 is left untouched and a teacher just chooses to move on to the topic-in-discussion (line 23) with completing the interaction with L3, during which another student comes up with another item in lines 23 to 24 . His earnest desire to be engage in the pedagogical performance stays unnoticed. It is for this reason that he looks very disappointed (Figure 17) in line 25. Thus, his gaze and ongoing finger-pointing demonstrates a learner's appeal to the next speakership. We never know what he is trying to say, but it is clear that he could've contributed to the interaction if a teacher noticed his nonverbal cues and handed over a turn to him. Unfortunately, it does not happen here and the teacher chose just to listen to other answer, shutting down an interactional space for L3's learning. It ends up taking away L3's opportunity to shape the contribution, hindering his learning.

Extract 3 also displays large hand movements and eye gaze as resources for a learner to interact with the teacher and peers. L3 employed multimodality to hold the floor at a particular point in the interaction. He helped a teacher to ask the question again by showing explicit embodied cues in line with his speech. It is significant to note how his colleagues reacted when he willingly responded to the teacher's questions but with no proper answer. When he looked downwards with his hand on head, other students recognized his explicit uncertainty. The uptake by his friends revealed that they take his non-vocal projection as 'in need of help', which is why they took the floor and added a further response. This is highly compelling evidence that shows how nonverbal codes create 'space for learning' (Walsh, 2011) among learners. Furthermore, it demonstrates that inaction for learners' appeal prevented learners from learning opportunity.

\section{Discussion}

It has been shown how learners enact and develop their CIC via the pedagogic task performance when they co-construct meanings and jointly establish understanding using linguistic and non-linguistic repertoires.

The spatial configuration created an interaction space which can allow them more enriching interactional resources like on-going finger-pointing to make the meaning more precise in line with the speech. The entwined resources enabled a learner 
extended space for reformulation and clarification, which helped interact with a teacher, thereby establishing intersubjectivity between participants (Extract 1). Other multimodal cues such as gaze, large head nodding and classroom artefact functioned as a mediator, by which learners take cues to decide the speakership of turn-taking in interaction (Extract 2). Through multimodal interplay, students were able to manage to hold the floor, recognise key signals that mark a transition relevance place, solicit and yield turn at a particular point in the activity. This is indicative of multimodality as a resource for learners to use to show their sufficient CIC. The final extract displayed that multimodality can either facilitate or block an interactional space from the learner's perspective. A learner's reliance on paralinguistic channels could elicit other students to interpret it as a sign for help, which promotes interaction among peers, whereas 'passing it over' by a teacher led to interactional breakdown, frustrating a learner, which ends up closing up 'a window for learning'. Learners that demonstrate CIC use multimodal interface that is both convergent to the teacher's pedagogical goal of the moment on-task and that is appropriate to the teacher. However, the simple moment that the teacher neither perceives a learner's appeal, nor shows proper CIC, using a language that is divergent to the pedagogic goal of the moment prevents learners from learning opportunity.

Thus, what learners are doing in the classroom with peers and a teacher can be made clear through modal complexity (Norris, 2004), the learner's finely tuned coordination of multimodal resources. We do things with things. That is, we express our opinions with resources we can employ. According to Streeck (1996), we should use whatever material comes our way when symbolizing something. It is the communication that counts because it is what we call "making sense" (p. 383). It might be a valuable strategy in particular in the classroom interaction context. If learners use verbal and nonverbal resources together, they may have better chances to help one another learn what should be learnt. Indeed, this study has demonstrated what multimodal resources learners rely on, how multimodality influences learning in relation to classroom interactional competence. Furthermore, it has shown how teachers should interpret learners' multimodal behaviours as Matusumoto and Dobs (2017) argued.

This calls on us as teachers to pay keen attention to classroom observations of multimodal cues to shed more light on our teaching practices in a way we can help learners make their learning more interactive and effective. It is because a failure to observe and recognize that a student wants to take a turn can lead to bored and frustrated students. According to Matsumoto and Dobs (2017), we can learn much about how students learn and how they respond to particular teaching strategies through close observation of learners in the process of learning. Thus, we need to monitor and react to student questions, comments, especially nonverbal projection, and facial expressions while teaching because students' every single movement provides us with a chance to interact. The perception on multimodality as an interactional resource enhances CIC in the ways in which both parties' interactional decision and subsequent actions in the classroom enhance learning and learning 
opportunity. A case in point could be typical perceptive tutors taking cues through multimodal behaviours to successfully interact and communicate with students in the classroom. They instinctively detect students who want to voice opinions. Students' simple gaze or movements alone, other than hand-raising causes them to negotiate meaning, which make the students reach understanding. They spot the moment in an almost automatic fashion, which looks like it is almost a subconscious and implicit process. Of course, it is not always the case but their perceived teaching practice do help students contribute to the class, having a tremendous impact on students' learning. Put simply, we can create space where learners shape contributions just by giving them a turn. Just as teachers' minimal response tokens such as 'mmhh and right' as evidence of their CIC (Walsh, 2011) help maintain the flow of the interaction, the multimodality between learners serves as evidence of learners' CIC to oil the wheels of the interactions.

Nevertheless, it seems that not every teacher is able to spot the moment, due to differences in teaching experience. Classrooms can be quite a busy environment to an inexperienced teacher in terms of noticing learners' nonverbal cues. It is demanding for the novice teacher to develop an ability to deal with multi-dimensional interaction occurring in the classroom, such as reacting, interacting and facilitating their learning as they are only preoccupied with explaining the relevant materials at hand. This prevents a learner from taking an opportunity to shape their contribution. The final extract shows a typical example of interactional breakdown where a learner obviously signals his wish to add on by depending on multimodal resources, but a teacher overlooks his turn-solicitation. The learner clearly displays his CIC in terms of his ability to hold the floor, whereas the teacher does not show his CIC when it comes to his skill to interact. Of course, it cannot be claimed for sure that the tutor's insufficient CIC impedes learning as it is hard to decide whether the teacher either intentionally ignored the learner's appeal or did not see the learner wishing to take a turn behind his back as the camera did not show the recording from teacher's perspective, but it can be said for sure that whatever reason, the student was trying to create his own 'space for learning' to no avail. That is, it is the teacher that both 'orchestrates the interaction' (Breen, 1998) and breaks the interaction.

This has two implications. First, we need training, in particular for classroom observation, which is an individual teaching skill that needs to be learned (Radford, 1990; Matsumoto \& Dobs, 2017; Walsh, 2006; 2011; 2013;). There is no doubt that it will not only raise awareness of the intricacies of multimodality, which we have taken for granted in the classroom interaction, but certainly help teachers give and take multimodal channels instructively, developing professionalism. It was found by both teachers and learners that multimodal behaviours such as gestures, gaze, postures, and facial expressions had critical impacts on learning. Nonetheless, foreign language teachers are less likely to use nonverbally visual devices during lessons in the classroom: not many teachers turned out to help learners understand specific points (Sime, 2006). This clearly shows that teachers should be aware of the importance and how big a role multimodality plays in the classroom interaction but they do not know 
how to use the one. It is for this reason that much care should be taken to develop education program where the teacher can improve the multimodal communication abilities. Thus, by developing an understanding of what role multimodality plays in classroom interaction, both teachers and learners might facilitate CIC which makes a big difference in learning.

The other is related to Self Evaluation of Teacher Talk (SETT). The SETT framework allows teachers to develop deeper understandings of the dialogic nature of classroom discourse (Walsh, 2006). The framework, however, does not claim to account for all aspects of classroom discourse-in-interaction. The interaction patterns are only teacher-fronted, without showing learner-learner interaction pattern and strategies. In other words, it is incapable of describing aspects where learners work independently of the teacher. In this sense, the findings might contribute to understanding in part how students themselves interact in the classroom, identifying one of features of students' CIC (SCIC); multimodality serves as valuable resources for 'opening a window for learning'.

\section{Conclusions}

This paper is limited in that it does not explain the full cluster of multimodal behaviours used and how they influence learning in the classroom context with small number of participants in analysis. It only covers part of multimodal resources and their impacts on learning. However, it is significant in that much attention has been paid to multimodality as an interactional resource among peers and their teacher in the classroom for CIC, and it can be a stepping stone to explore more features of SCIC that have potential influences on learning. Indeed, many researchers are known to have currently characterized interactional competence as the fifth skill in addition to four skills. Multimodality has also been taken and conceptualised as an important marking criteria in oral proficiency interviews (Briegel-Jones, 2013), and the IELTS research committee all over the world acknowledge there is much work to be done in terms of taking nonverbal behaviour in a speaking test into consideration.

Clearly, it is important for teachers to raise awareness of the intricacies of multimodality, understand how it functions and how it influences learning, and put their lessons into practice to improve their CIC, as well as students' one. That explains why attempts have been made in this paper to demonstrate what multimodal resources are used by learners, how they impact learning in the classroom and how teachers can make changes to their teaching practices. There is no 'one-fits-for-all' to change and improve, like any other professional development. However, understanding a specific context and developing skills appropriate to that context play a key role in our endeavour towards growing up to be a better teacher. Understanding multimodality as CIC resources in the classroom interaction and improving how it is managed are central to improving our teaching and feeding our students.

\section{Acknowledgements}


This paper has been improved by the help of an academic staff and $\mathrm{PhD}$ colleagues. I would like to thank Professor Steve Walsh for offering a quality data and invaluable feedback, and also thank Kazuki and Nur for their insightful peer review. Finally, I would like to thank anonymous reviewers at Eurasian Journal of Applied Linguistics for their comments and suggestions which served to increase the quality and clarity of this paper.

\section{References}

Applebaum, E., Egel, A.L., Koegel, R.L., \& Imhoff, B. (1979). Measuring musical abilities of autistic children. Journal of Autism and Developmental Disorders, 9, pp. 279-285.

Breen, M.P. (1998). Navigating the discourse: on what is learned in the language classroom. In W.A. Renandya, \& G.M. Jacobs, (Eds.) Learners and Language Learning. Singapore: SEAMO Regional Language Centre.

Briegel-Jones, L. (2013). An investigation into nonverbal behaviour in the oral proficiency interview. Newcastle University.

Can Daşkın, N. (2015) Shaping learner contributions in an EFL classroom: Implications for L2 classroom interactional competence. Classroom Discourse, 6(1), pp. 33-56.

Davis, B.G. (2009) Tools for teaching (2nd ed.). Sanfrancisco, CA: Jossy-Bass.

Escobar Urmeneta, C. (2013). Learning to become a CLIL teacher: teaching, reflection and professional development. International Journal of Bilingual Education and Bilingualism, 16(3), pp. 334-353.

Escobar Urmeneta, C., \& Evnitskaya, N. (2014) 'Do you know Actimel?' The adaptive nature of dialogic teacher-led discussions in the CLIL science classroom: a case study. The Language Learning Journal, 42(2), pp. 165-180.

Eskildsen, S. W., \& Wagner, J. (2013). Recurring and shared gestures in the L2 classroom: resources for teaching and learning. European Journal of Applied Linguistics, 1(1), pp. 139161.

Goodwin, C. (1979) The interactive construction of a sentence in natural conversation. In G. Psathas (Ed.), Everyday Language: Studies in Ethnomethodology (pp. 97-121). New York: Irvington.

Goodwin, C. (1981). Conversational Organization. New York: Academic.

Gullberg, M. (1998). Gesture as a communication strategy in second language discourse. A study of learners' French and Swedish. Lund: Lund University Press.

Hennessy, S. (2011). The role of digital artefacts on the interactive whiteboard in supporting classroom dialogue. Journal of Computer Assisted Learning, 27(6), pp. 463-489.

Houser, M.L., \& Frymier, A.B. (2009). The role of student characteristics and teachers behaviors in students' learner empowerment. Communication in Education, 58(1), pp. 3553.

Iwasaki, S. (2015). Collaboratively organized stancetaking in Japanese: Sharing and negotiating stance within the turn constructional unit. Journal of Pragmatics, 83, pp. 104119.

Keevallik, L. (2014). Turn organization and bodily-vocal demonstrations. Journal of Pragmatics, 65, pp. 103-120.

Knight, D. (2011). The future of multimodal corpora. Revista Brasileira de Linguística Aplicada, 11, pp. 391-415.

Koole, T., \& Elbers, E. (2014). Responsiveness in teacher explanations: A conversation analytical perspective on scaffolding. Linguistics and Education, 26(0), pp. 57-69. 
Kupetz, M. (2011). Multimodal resources in students' explanations in CLIL interaction. Novitas ROYAL, 5(1), pp. 121-142.

Liszkowski, U. (2010). Before L1: A differentiated perspective on infant gestures. In M. Gullberg, \& K. De Bot (Eds.), Gestures in Language Development. Amsterdam/Philadelphia John Benjamins.

Markee, N., \& Kasper, G. (2004) Classroom talks: An introduction. The Modern Language Journal, 88(4), pp. 491-500.

Matsumoto, Y., \& Dobs, A.M. (2017). Pedagogical gestures as interactional resources for teaching and learning tense and aspect in the ESL grammar classroom. Language Learning, 67(1), pp. 7-42.

Mondada, L. (2006). Participants' online analysis and multimodal practices: projecting the end of the turn and the closing of the sequence. Discourse Studies, 8(1), pp. 117-129.

Mondada, L. (2007). Multimodal resources for turn-taking: pointing and the emergence of possible next speakers. Discourse Studies, 9(2), pp. 194-225.

Mondada, L. (2009). Emergent focused interactions in public places: A systematic analysis of the multimodal achievement of a common interactional space. Journal of Pragmatics, 41(10), pp. 1977-1997.

Mondada, L. (2011). The interactional production of multiple spatialities within a participatory democracy meeting. Social Semiotics, 21(2), pp. 289-316.

Mortensen, K. (2008) 'Selecting next-speaker in the second language classroom: How to find a willing next-speaker in planned activities. Journal of Applied Linguistics, 5(1), pp. 55-79.

Mortensen, K. (2009) Establishing recipiency in pre-beginning position in the second language cassroom. Discourse Processes, 46(5), pp. 491-515.

Norris, S. (2004). Analyzing multimodal interaction. London: RoutledgeFalmer.

Radford, K.W. (1990). Observing the class. Education Canada, 30, pp. 36-39.

Sert, O. (2011). A micro-analytic investigation of claims of insufficient knowledge in EAL classrooms. Newcastle University.

Sert, O. (2015). Social interaction and L2 classroom discourse. Edinburgh: Edinburgh University Press.

Schegloff, E. A. (1984). On some questions and ambiguities in conversation. In J. M. Atkinson, \& J. Heritage (Eds.) Structures of Social Action. Cambridge: Cambridge University Press.

Sime, D. (2006). What do learners make of teachers' gestures in the language classroom?', International Review of Applied Linguistics in Language Teaching (IRAL), 44(2), pp. 211-230.

Stivers, T., \& Sidnell, J. (2005). Introduction: Multimodal interaction, Semiotica, 156(1), pp. 1-20.

Ten Have, P. (2007). Doing conversation analysis (2 ${ }^{\text {nd }}$ ed.). London: SAGE.

Vygotsky, L.S., \& Cole, M. (1978). Mind in society: the development of higher psychological processes. Cambridge: Harvard University Press.

Walsh, S. (2006). Investigating classroom discourse. London: Routledge.

Walsh, S. (2011). Exploring classroom discourse : language in action. London: Routledge.

Walsh, S. (2013). Classroom Discourse and Teacher Development. Edinburgh: Edinburgh University press.

Webb, J.M., Diana, E.M., Luft, P., Brooks, E.W., \& Brennan, E.L. (1997). Influence of pedagogical expertise and feedback on assessing student comprehension from nonverbal behavior. Journal of Educational Research, 91(2), pp. 89-97.

\section{Copyrights}

Copyright for this article is retained by the author(s), with first publication rights granted to the Journal.

This is an open-access article distributed under the terms and conditions of the Creative Commons Attribution license (CC BY-NC-ND) (http://creativecommons.org/licenses/by-nc-nd/4.0/). 